\title{
An Experience Survey Report on Post Caesarean Complications among Young Women
}

\author{
Saumya P Jose', Tobin Joseph ${ }^{2}$ \\ ${ }^{1}$ Associate Professor, Vidyarathna College of Nursing, Uduppi, Mangalore, Karnataka - 576101 \\ ${ }^{2}$ Professor, Head of the Department, Indira College of Nursing, Falnir, Mangalore, Karnataka - 575002
}

Corresponding Author: Tobin Joseph

\begin{abstract}
Aim: To assess the post caesarean complications among young women through a survey study.

Background: Caesarean section delivery has many adverse effects in the post natal period and later including pain, muscle weakness, reduced endurance, adverse reactions from anaesthesia and difficulty in breast feeding. There are several studies reported the healthrelated complications following caesarean section. However it is not been fully understood the various complications and its reasons.

Design: An explorative cross sectional survey study.

Method: participants were identified based on the inclusion criteria. Information on caesarean section delivery related complications and experience were gathered.

Conclusion: The complications following the caesarean survey may increase the risk of physical difficulties, incidence of lower back pain, reduced abdominal strength, and difficulty in selfcare activities.
\end{abstract}

Keywords: caesarean delivery, complications, child labour, Postpartum period pain.

\section{INTRODUCTION}

Providing a safe pregnancy and Motherhood occupies a significant role. Most of the recent medical literature states that there is an increase in the rate of Caesarean section delivery. Most identified reason behind this is various complications in the prenatal and perinatal period. In addition to this previous caesarean section delivery is also considered as one of the contributing factor. Ensuring a safe motherhood and child survival is the responsibility of the whole health care professionals. The government of various countries has been employed maternal and child care programs across different parts of the world. ${ }^{1}$ Even though many health related complications are reported following caesarean section delivery. It is one of the safe-guard the health of the newborn and the mother during complicated delivery. delivery in such cases a cesarean section could reduce the risk of potential trauma birth asphyxia and breech presentation most of the cases presented in section has been executed a with its maximum safety but is it is also associated with higher rate of morbidity and maternal complications. ${ }^{2}$ Most of the cases caesarean section has been executed with its maximum safety, but it is also associated with higher rate of morbidity and maternal complications. There are several studies reported the health related complications following caesarean section in the earlier period was women experience the anaesthetic side effects haemorrhage, bladder and bowel injuries etc. furthermore babies born By Cesarean Section are also subjected to high risk morbidity including fetal injury and fracture. There are plenty of contributing factor for opting caesarean Section delivery including biomedical factors, demographic, socio economic factors, psychological variables and previous caesarean Section delivery. ${ }^{3,4}$ The present survey intended to 
add information to the existing medical literature regarding the various post caesarean complications experienced by women.

\section{METHODOLOGY}

Objectives: To assess the various post natal complications following caesarean section delivery among the young women.

Methods: A questionnaire has been prepared with respect to complications following caesarean section delivery. This consists of 10 close ended questions; participants are asked to mention yes or no for each questions. The survey was distributed to 60 women aged between 18 to 35 who were willing to participate in the study. Women with a post caesarean period up to 9 months were included in the study.

Sampling technique: convenient sampling

Sample size: 60
Study duration: 8 months

\section{RESULTS}

The survey was conducted among 60 voluntary participants. We identified that around $75 \%$ of the women experienced pain during the post natal period. $20 \%$ of them underwent various psychological distress and very less got bowel and bladder injury. It was approximately $8.33 \%$. Half of the women experienced anaesthesia side effects immediately following the caesarean section delivery. One of the major complications noted among the women was the incidence of lower back pain and the incidence was $58 \%$, that was found to have a long term effects. Very few had felt headache and $28 \%$ of them had issues while breast feeding. Their self care activities, sleep was also found to interfere. The quality of life also had an impact after the caesarean section delivery.

Table 1: Response of participants

\begin{tabular}{|c|l|c|}
\hline SI no & Items in the questionnaire & Percentage of response $(\mathbf{n}=\mathbf{6 0}) \mathbf{\%}$ \\
\hline 1 & Pain & 75 \\
\hline 2 & Psychological distress & 20 \\
\hline 3 & Anaesthesia side effects & 8.33 \\
\hline 4 & Bladder and bowel injuries & 50 \\
\hline 5 & Lower back pain & 58 \\
\hline 6 & Head ache & 8.33 \\
\hline 7 & Issues with breast feeding & 28 \\
\hline 8 & Sleep & 20 \\
\hline 9 & Self care activities & 46 \\
\hline 10 & Overall quality of life & 45 \\
\hline
\end{tabular}

\section{DISCUSSION}

The presented study evaluated the post caesarean section delivery complications among the young women. The various complications following the surgery includes pain, psychological distress, bladder and bowel injury, anaesthesia complications, low back pain, head ache, difficulty with breast feeding, sleep disturbances, problems encountered with self-care activities and reduced quality of life. In this most of the women had experienced low back pain, caesarean section incision pain and difficulty to carryout self care activities. Approximately Anaesthesia complications single or in the pain numbness minor card or injury where found in 30 to 5050 percentage of the population. 5,6 Many other comments made by the women related to the spiralling effect of interventions during labour. Some women rated their experience negatively because they had interventions they didn't want while others stated being forced or 'hassled' into them. ${ }^{7}$ Women defined feeling disempowered as the use of drugs for induction and epidurals. Women also expressed how the actual surgical procedure of having a Caesarean section paid to their trauma. Birthing in the operating theatre was seen as 'clinical' as contrasting to natural and normal. Some women reported feeling totally spontaneous for the preparation and procedures connected with 
major abdominal surgery. The available literature shows that there has been a four to six fold increase in caesarean section deliveries during the last two to three decades. 8 The tendency to undergo caesarean section was positively related with the number of antenatal care visits. The proportion of caesarean sections is almost double for mothers who had over 5 times the antenatal care visits compared to those with fewer visits. ${ }^{10}$

\section{CONCLUSION}

The study concluded that Caesarean section delivery results in various long and short term complications among the women. Maternity Health care professionals should identify such possible complications and should offer enhanced attention and care at the earliest to overcome these issues.

Acknowledgement: The authors would like to acknowledge all the participants of the study

\section{Conflict of Interest: None declared}

\section{Source of Funding: None}

\section{REFERENCES}

1. Porter M, Van Teijlingen E, Chi Ying Yip L, Bhattacharya S. Satisfaction with cesarean section: Qualitative analysis of open-ended questions in a large postal survey. Birth. 2007 Jun;34(2):148-54.

2. Dharmalingam TK, Zainuddin NA. Survey on maternal satisfaction in receiving spinal anaesthesia for caesarean section. The Malaysian journal of medical sciences: MJMS. 2013 May;20(3):51.

3. Sobhy S, Arroyo-Manzano D, Murugesu N, Karthikeyan G, Kumar V, Kaur I, Fernandez E, Gundabattula SR, Betran AP, Khan K, Zamora J. Maternal and perinatal mortality and complications associated with caesarean section in low-income and middle-income countries: a systematic review and meta-analysis. The Lancet. 2019 May 11;393(10184):1973-82.

4. Corcoran S, Jackson V, Coulter-Smith S, Loughrey J, McKenna P, Cafferkey M. Surgical site infection after cesarean section: implementing 3 changes to improve the quality of patient care. American journal of infection control. 2013 Dec 1;41(12): 1258-63.

5. Ugwu EO, Obioha KC, Okezie OA, Ugwu AO. A five-year survey of caesarean delivery at a Nigerian tertiary hospital. Annals of medical and health sciences research. 2011;1(1):77-84.

6. Carvalho B, Cohen SE, Lipman SS, Fuller A, Mathusamy AD, Macario A. Patient preferences for anesthesia outcomes associated with cesarean delivery. Anesthesia \& Analgesia. 2005 Oct 1;101(4):1182-7.

7. Shah A, Fawole B, M'imunya JM, Amokrane F, Nafiou I, Wolomby JJ, Mugerwa K, Neves I, Nguti R, Kublickas M, Mathai M. Cesarean delivery outcomes from the WHO global survey on maternal and perinatal health in Africa. International Journal of Gynecology \& Obstetrics. 2009 Dec 1;107(3):191-7.

8. Brown A, Jordan S. Impact of birth complications on breastfeeding duration: an internet survey. Journal of advanced nursing. 2013 Apr;69(4):828-39.

9. Fenwick J, Gamble J, Mawson J. Women's experiences of Caesarean section and vaginal birth after Caesarian: A Birthrites initiative. International journal of nursing practice. 2003 Feb;9(1):10-7.

10. Padmadas SS, Nair SB, KR AK. Caesarean section delivery in Kerala, India: evidence from a national family health survey. Social Science \& Medicine. 2000 Aug 15;51 (4): 511-21.

How to cite this article: Jose SP, Joseph T. An experience survey report on post caesarean complications among young women. International Journal of Science \& Healthcare Research. 2021; 6(3): 264-266. DOI: https:// doi.org/10.52403/ijshr.20210745 